\title{
Antibody isotype analysis of malaria-nematode co-infection: problems and solutions associated with cross-reactivity
}

\author{
Karen J Fairlie-Clarke ${ }^{1 *}$, Tracey J Lamb², Jean Langhorne ${ }^{3}$, Andrea L Graham ${ }^{1,4}$, Judith E Allen ${ }^{1}$
}

\begin{abstract}
Background: Antibody isotype responses can be useful as indicators of immune bias during infection. In studies of parasite co-infection however, interpretation of immune bias is complicated by the occurrence of cross-reactive antibodies. To confidently attribute shifts in immune bias to the presence of a co-infecting parasite, we suggest practical approaches to account for antibody cross-reactivity. The potential for cross-reactive antibodies to influence disease outcome is also discussed.

Results: Utilising two murine models of malaria-helminth co-infection we analysed antibody responses of mice singly- or co-infected with Plasmodium chabaudi chabaudi and Nippostrongylus brasiliensis or Litomosoides sigmodontis. We observed cross-reactive antibody responses that recognised antigens from both pathogens irrespective of whether crude parasite antigen preparations or purified recombinant proteins were used in ELISA. These responses were not apparent in control mice. The relative strength of cross-reactive versus antigen-specific responses was determined by calculating antibody titre. In addition, we analysed antibody binding to periodatetreated antigens, to distinguish responses targeted to protein versus carbohydrate moieties. Periodate treatment affected both antigen-specific and cross-reactive responses. For example, malaria-induced cross-reactive lgG1 responses were found to target the carbohydrate component of the helminth antigen, as they were not detected following periodate treatment. Interestingly, periodate treatment of recombinant malaria antigen Merozoite Surface Protein-1 ${ }_{19}\left(\mathrm{MSP}_{-1}{ }_{19}\right)$ resulted in increased detection of antigen-specific lgG2a responses in malaria-infected mice. This suggests that glycosylation may have been masking protein epitopes and that periodate-treated MSP-1 ${ }_{19}$ may more closely reflect the natural non-glycosylated antigen seen during infection.

Conclusions: In order to utilize antibody isotypes as a measure of immune bias during co-infection studies, it is important to dissect antigen-specific from cross-reactive antibody responses. Calculating antibody titre, rather than using a single dilution of serum, as a measure of the relative strength of the response, largely accomplished this. Elimination of the carbohydrate moiety of an antigen that can often be the target of cross-reactive antibodies also proved useful.
\end{abstract}

\section{Background}

The geographical and socio-economic distribution of malaria overlaps with areas in which a number of helminth parasites are also endemic. It is the norm in these areas for co-infection to occur and a growing body of literature reflects this [1-12]. The influence of co-infection on the immune response may result in either

\footnotetext{
* Correspondence: Karen.Fairlie-Clarke@ed.ac.uk

'Institutes of Evolution, Immunology and Infection Research, School of Biological Sciences, King's Buildings, University of Edinburgh, West Mains Road, Edinburgh, EH9 3JT, UK
}

exacerbation or amelioration of disease [13-15]. It is therefore crucial to understand the host-parasite relationship in the context of multiple infections, if vaccine design and drug administration programmes are to be managed effectively [16]. Animal models accurately reflect many pathological aspects of malaria-helminth co-infection with regard to impact on disease outcome and also provide the opportunity to further examine immunological mechanisms in detail [17-20].

We previously undertook an investigation to assess the impact of a pre-existing chronic nematode infection on

\section{C) Biomed Central}


malaria-related pathology, utilising the rodent malaria Plasmodium chabaudi chabaudi (Pcc) and the rodent filarial nematode Litomosoides sigmodontis (Ls) [21]. We found that co-infected mice (Pcc-Ls), particularly those that did not have blood microfilaremia, had exacerbated immunopathology. This was associated with increased interferon-gamma (IFN- $\gamma$ ) responsiveness but was independent of $P c c$ parasitemia [21]. One of the primary objectives in our previous malaria-nematode co-infection studies was to gather antigen-specific $\mathrm{T}$-cell data to determine whether nematode infection could alter the cytokine bias of the $P c c$-specific T lymphocyte response towards Th1 and conversely, whether a potent Th1 response could alter the Th2 bias of the nematode-specific response.

Cytokine production by antigen specific T-cells can be difficult to assess during malaria, due to immune suppression associated with the peak of infection and apoptosis of splenocytes [22]. Additionally, the complex nature of the target antigen (Pcc-infected red blood cells) is a further complicating factor. Thus, gathering antigen-specific $\mathrm{T}$-cell data remains a technical challenge of studying immunity to malaria particularly in human studies where there is the additional challenge of obtaining and maintaining lymphocytes in the field.

Here we focus on the dissection and interpretation of parasite antigen-specific antibody responses as an alternative to T-cell analysis. Antibodies of the IgG2a isotype are mainly produced by $\mathrm{B}$ cells in response to IFN- $\gamma$ in mice [23-25] whereas the Th2 cytokine IL-4 switches B cells to produce IgG1 $[24,26]$. Although the generation of IgG1 as a marker for Th2 cells is less definitive than IgG2a as a marker of a Th1-type response, the ratio of IgG1 to IgG2a provides a powerful indicator of immune bias [27-30]. Measurement of antibodies can also be achieved with smaller sample volumes and poses fewer technical challenges than T-cell recall assays. Furthermore, antibody analysis can provide information on the fuller history of infection as it reflects cumulative immunological activity, whereas cytokine responses of T-cells are an ex-vivo 'snapshot' that can more readily be altered by changes in the timing of sampling both in vivo and in vitro. Antibody analyses of co-infected animals might therefore provide evidence of overall Th1Th2 cell cross-regulation even when cytokine analyses may not.

In addition to their use as indicators of cytokine bias during infection, antibody isotypes have direct functional relevance to disease severity in helminth-malaria coinfection. Antibodies are absolutely required for the ultimate clearance of malaria parasites [31]. In mice, antibodies of the cytophilic isotype IgG2a have been shown to recognise infected erythrocytes [32] and facilitate their destruction by phagocytes [33]. Similarly, in humans IgG1 and IgG3 are associated with enhanced parasite clearance [34]. If helminth co-infection alters antibody class-switching and consequently the production of malaria-specific cytophilic antibodies then the resolution of malaria infection may be affected. Indeed, co-infection with the gastro-intestinal nematode Heligomosoides polygyrus reduced Pcc-specific IgG2a responses and resulted in exacerbated malaria parasitemia [18]. There are also important implications for vaccine efficacy and administration. For example, immunisation that protected mice from malaria failed to do so in mice that also harboured a nematode infection [35].

In this study, the characterisation of antibody isotype responses as an indicator of cytokine bias during coinfection has proved unexpectedly challenging due to the production of cross-reactive antibodies induced by single-species infection. To establish the real effect of coinfection on the Th1/Th2 immune bias from non-specific reactivity to antigen we needed to determine how robust the cross-reactive responses were in comparison to the antigen-specific. We demonstrate that a combination of calculating antibody titre, from a dilution series of test sera, and periodate treatment of the parasite antigens can control for most cross-reactivity. The magnitude and robustness of some cross-reactivity, however merits further investigation to explore the potential function of these responses during co-infection.

\section{Methods}

\section{Hosts, parasites and experimental infection}

Specific pathogen free, 8-10 week old female BALB/c mice (Harlan, UK) were maintained in individually ventilated cages on diet $41 \mathrm{~b}$ ad lib in a $12 \mathrm{~h}: 12 \mathrm{~h}$ light-dark cycle. All experiments were carried out in accordance with the animals (Scientific Procedures) Act 1986, and were approved by the UK Home Office inspectorate and institutional review committee.

Pcc clone AS was originally isolated from thicket rats (Thamnomys rutilans) and was cloned by serial dilution and passage [36]. Parasites were recovered from frozen blood stabilates by passage through donor mice. Experimental parasite inoculations were prepared from donor mice by diluting blood in calf serum solution $(50 \%$ heatinactivated foetal calf serum, 50\% Ringer's solution [27 $\mathrm{mM} \mathrm{KCl}, 27 \mathrm{mM} \mathrm{CaCl} 2,0.15 \mathrm{M} \mathrm{NaCl}, 20$ units heparin per mouse]). Each mouse received $0.1 \mathrm{ml}$ of inoculum intraperitoneally (i.p) corresponding to an infective dose of $1 \times 10^{6}$ or $1 \times 10^{5}$ parasitized red blood cells (RBC), depending on the experiment. An inoculum of naïve $\mathrm{RBC}$ was given as a control for erythrocyte proteins.

The filarial nematode $L s$ was maintained by cyclical passage between gerbils (Meriones unguiculatus) and mites (Ornithonyssus bacoti) as described previously [37]. Infection was initiated by subcutaneous (s.c) 
injection of 25 infective (L3) larvae. For co-infection experiments in which the influence of malaria on chronic nematode infection was addressed, $1 \times 10^{6} \mathrm{Pcc}$ parasitized RBC were introduced i.p on Day 60 of an established $L s$ infection and mice were sacrificed on day 20 post- $P c c$ infection, as described previously [21]. Whole blood was collected from the brachial artery and serum recovered after clotting at room temperature.

$\mathrm{Nb}$ worms were maintained by serial passage through Sprague-Dawley rats. L3 larvae were obtained by culturing the faeces of infected rats at $26^{\circ} \mathrm{C}$ for a minimum of 5 days [38]. For acute nematode-malaria co-infection, infection was initiated by s.c injection of 200 infective (L3) larvae on the same day that Pcc was introduced by inoculation i.p of $1 \times 10^{5}$ parasitized RBC. Mice were sacrificed on Day 20 post-infection under terminal anaesthesia. Whole blood was collected from the brachial artery and was separated using Sera Sieve (Hughes \& Hughes Ltd).

\section{Antigens}

Two malaria antigens were used in this study: a recombinant protein and a crude antigen homogenate prepared from parasitized erythrocytes. The recombinant Merozoite Surface Protein-1 $1_{19}$ (MSP- $1_{19}$ ) was originally sequenced, cloned and expressed from Pcc AS clone, as described previously [39]. In brief, the MSP- $1_{19}$ nucleotide sequence was inserted into Pichia pastoris vector pIC9K and protein expression carried out in Pichia pastoris strain SMD1169. This antigen was used in ELISA at a concentration of $1 \mu \mathrm{g} / \mathrm{ml}$.

The crude malaria homogenate - lysed Pcc parasitized red blood cell extract (pRBC) - was prepared from whole blood of mice with a parasitemia in excess of $20 \%$. Mice were bled by cardiac puncture with a heparinised syringe and blood stored at $-80^{\circ} \mathrm{C}$ prior to 3 rounds of freezethaw to lyse the parasitized red blood cells. The lysed cells were sonicated, on ice, twice for $30 \mathrm{sec}$ at $10 \mathrm{Amp}$ and centrifuged at $16060 \mathrm{~g}$ for $10 \mathrm{~min}$. The supernatant was stored at $-80^{\circ} \mathrm{C}$. Similarly, a naïve red blood cell extract (nRBC) was prepared as a control for RBC proteins; responses to this antigen amongst infected mice were indistinguishable from naïve (data not shown). In the $L s$ experiments this antigen was used in ELISA at 0.5 $\mu \mathrm{g} / \mathrm{ml}$ and in the $N b$ experiments at $5 \mu \mathrm{g} / \mathrm{ml}$.

$L s$ and $\mathrm{Nb}$ extracts (LsA and $\mathrm{NbA}$ ) were prepared by homogenisation of adult nematodes in PBS. The somatic extracts were centrifuged at $1000 \mathrm{~g}$ for $20 \mathrm{mins}$ and the pellet discarded. The extract was stored at $-20^{\circ} \mathrm{C}$. LsA was used in ELISA at $0.5 \mu \mathrm{g} / \mathrm{ml}$ and NbA at $5 \mu \mathrm{g} / \mathrm{ml}$.

\section{Antibody detection}

ELISA was used to measure antigen-specific IgG antibodies in the serum of nematode-infected, Pcc-infected or co-infected mice. In the Pcc-Ls study, sera were added in a serial dilution $1 / 100-1 / 400$ and a dilution was then chosen whereby all samples fell in the linear range of the curve; for IgG1, a dilution of $1 / 200$ and for IgG2a $1 / 100$. For the subsequent $P c c-N b$ study, serum samples were added in a serial dilution 1/50 - 1/819200. Antibody titres were calculated as the reciprocal of the greatest dilution at which optical density (O.D) was greater than the mean plus 3 standard deviations of the O.D values observed for control mouse sera at $1 / 200$ dilution.

Antibody responses to MSP- $1_{19}, \mathrm{pRBC}, \mathrm{NbA}$ or LsA were determined for IgG isotypes IgG1, IgG2a, and IgG3. 96 well maxisorp immunoplates (Nunc) were coated at $4^{\circ} \mathrm{C}$ overnight with either recombinant or crude antigens at the concentrations indicated (see Antigens section) in $0.06 \mathrm{M}$ carbonate buffer $(0.04 \mathrm{M}$ $\left.\mathrm{NaHCO}_{3}, 0.02 \mathrm{M} \mathrm{NaCO}_{3}, \mathrm{pH} 9.6\right)$ in a final volume of $50 \mu \mathrm{l}$ per well. Non-specific binding was blocked with $5 \%$ FCS in carbonate buffer $(200 \mu \mathrm{l} /$ well $)$ for 2 hours at $37^{\circ} \mathrm{C}$. Wells were washed three times in Tris buffered saline with $0.1 \%$ Tween (TBST) after each step. Serum samples were added in serial dilutions as indicated using TBST as a diluent, in a final volume of $75 \mu \mathrm{l}$ per well and incubated for 2 hours at $37^{\circ} \mathrm{C}$. Isotype specific detection antibodies were diluted in TBST in a final volume of $50 \mu \mathrm{l}$ per well. For IgG1, HRP conjugated goat anti-mouse IgG1 (Southern Biotech 1070-05) was used at 1/6000, HRP conjugated goat anti-mouse IgG2a (Southern Biotech 1080-05) at 1/4000 and HRP conjugated goat anti-mouse IgG3 (Southern Biotech 1100-05) was used at $1 / 1000$. Plates were incubated for 1 hour at $37^{\circ} \mathrm{C}$. An additional wash in distilled water was carried out before developing with ABTS peroxide substrate (Insight Biotechnology), $100 \mu \mathrm{l}$ per well, at room temperature for 20 minutes. O.D was read at $405 \mathrm{~nm}$ using a spectrophotometer.

Polyclonal IgE levels were determined by sandwich ELISA. 96 well maxisorp immunoplates (Nunc) were coated overnight at $4^{\circ} \mathrm{C}$ with $100 \mu \mathrm{l}$ of IgE capture antibody $(2 \mu \mathrm{g} / \mathrm{ml}$; clone R35-72 Pharmingen) diluted in carbonate buffer. Plates were blocked with $5 \%$ non-fat skimmed milk in carbonate buffer for $2 \mathrm{hr}$ at $37^{\circ} \mathrm{C}$. Plates were washed $5 \times$ in TBST before addition of sera at $1 / 10$ and $1 / 20$ dilutions in a final volume of $50 \mu \mathrm{l} /$ well and left overnight at $4{ }^{\circ} \mathrm{C}$. For the standard curve two- fold serial dilutions of purified mouse IgE, $\kappa$ monoclonal isotype standard (Pharmingen) were used. After 5 washes in TBST, $100 \mu \mathrm{l}$ of biotinylated detection antibody ( $2 \mu \mathrm{g} / \mathrm{ml}$; clone R35-118 Pharmingen) diluted in TBST with $5 \%$ FCS was added and plates left at $37^{\circ} \mathrm{C}$ for 90 mins. Plates were washed $5 \times$ in TBST prior to incubation with ExtrAvidin peroxidase (SIGMA), diluted 1:8000 in TBST with $0.5 \%$ FCS, for 30 mins at $37^{\circ} \mathrm{C}$. 
After a final wash in distilled water, plates were developed with $100 \mu \mathrm{l}$ TMB microwell peroxidase substrate system (Insight Biotechnology Ltd) and read at $650 \mathrm{~nm}$.

In order to determine the extent to which carbohydrate or protein moieties contributed to the antibody response the antigens were pre-treated with periodate. Antigen-specific IgG1, IgG2a and IgG3 antibodies were measured in response to antigens treated with periodate. The ELISA was carried out as detailed for the $\mathrm{Nb}$ coinfection experiment with untreated antigens but the following additional steps were included after blocking with 5\% FCS: carbonate buffer, prior to sample addition. TBST wash $(\times 3)$ was followed by the addition of $10 \mathrm{mM}$ sodium (meta) periodate diluted in $50 \mathrm{mM}$ sodium acetate in a final volume of $100 \mu \mathrm{l} /$ well. Plates were incubated at $37^{\circ} \mathrm{C}$ for 1 hour and then washed in $50 \mathrm{mM}$ sodium acetate. To stop the activity of periodate, $100 \mu \mathrm{l}$ of $50 \mathrm{mM}$ sodium borohydride solution was added to each well.

\section{Statistical Analysis}

General linear statistical models allowed us to frame and test questions such that we could determine whether differences in infection status and/or presence of carbohydrate antigen explained the observed variation in antibody responses. For more detailed explanation of the statistical methods employed see Grafen and Hails [40]. Infection status and treatment with periodate (or not) were included as categorical factors and their ability to predict antibody response was formally evaluated via Analysis of Variance (ANOVA). The serial dilution of sera in an ELISA produces ordinal data, which were $\log _{10}$ transformed prior to analysis to ensure the data were approximately normally distributed, in accordance with the requirements of linear models. Analyses were carried out using the statistical package JMP 5.1 (SAS). The maximal model was fitted first and minimal models were obtained by sequentially removing non-significant terms ( $\mathrm{P}$-value $>0.05)$, beginning with interactions. Finally, whenever a factor was significant $(P<0.05)$, an All Pairs Tukey post-hoc test was carried out to identify which groups of mice differed significantly in antibody induction, with respect to infection status or periodate treatment.

\section{Results}

Antibody isotype responses are skewed by malaria-filaria co-infection but cross-reactivity confounds data interpretation

We had previously used a model of $P c c$-nematode coinfection in which $P c c$ is introduced into mice with preexisting chronic $L s$ infection to investigate the dynamics of infection with regard to parasitological outcome and cytokine bias [21]. In the Pcc-Ls model the peak of malaria parasitemia was controlled by day 10 and resolved by day 14 post Pcc-infection. For this study, we envisaged that analysis of the antibody isotype response from these mice would provide a method to rapidly and quantitatively assess immune bias. We thus asked whether we could use antibody isotype ELISA for IgG2a and IgG1 to address whether nematode infection would skew the Th1 cell response to $P c c$ to a more Th2 cell biased response. Conversely, we wished to address whether the powerful Th1 cell response induced by malaria would have the capacity to alter an established IgG1 response to a nematode infection. As is common practice in many studies [41-48], especially with large sample sizes as in this study, the ELISAs were performed with a fixed serum concentration derived from the linear point in a dilution series.

As expected from previous studies [49-51], we were able to detect an IgG1 response against LsA in $L s$ mice. Co-infected (Pcc-Ls) mice also produced LsA-specific IgG1, but it was reduced in magnitude compared to the Ls mice (Fig 1Ai). Thus co-infection with Pcc appeared to down-regulate the anti-Ls specific IgG1 response. It also appeared that responses in Pcc-Ls mice were further biased toward a Th1 cell response through the induction of IgG2a to LsA (Fig 1Aii). Also as expected [32,52], Pcc mice mounted highly biased Th1-cell responses as indicated by the predominance of $P c c$ (pRBC)-specific IgG2a over IgG1 (Fig 1B). Once again, Pcc-Ls mice appeared to alter this bias by increasing the amount of $\mathrm{pRBC}$-specific IgG1 in comparison to the Pcc mice (Fig 1Bi).

At first glance, the results strongly suggested that the isotype and hence cytokine bias of each single-species infection was significantly impacted by co-infection. In support of this, polyclonal IgE was highest in $L s$ mice and absent in $P c c$ mice with Pcc-Ls mice exhibiting an intermediate level (Fig. 1C) although Pcc-Ls mice did not differ statistically from $L s$ mice in this polyclonal analysis. However, it was apparent that Pcc mice were exhibiting sizable antibody responses to LsA ( $\mathrm{X}_{1}$ in Fig 1Aii) and conversely $L s$ mice were exhibiting strong antibody responses to pRBC ( $\mathrm{X}_{2}$ in Fig $\left.1 \mathrm{Bi}\right)$. Western blot analysis confirmed that these $L s$-induced cross-reactive responses were directed against the parasite rather than the RBC (data not shown). We thus had to ask whether the shift away from LsA-specific IgG1 toward IgG2a responses in the Pcc-Ls mice was due to the influence of IFN- $\gamma$ on the $L s$-induced response or simply reflected the presence of cross-reactive Pcc-induced IgG2a responses to LsA. Conversely, was the apparent increase in pRBC-specific IgG1 responses in Pcc-Ls mice due to $L s$-induced antibodies that cross-reacted with infected red blood cells? Because serum titres had not been determined in this study, we could not assess the relative strength of cross-reactive versus antigen-specific 


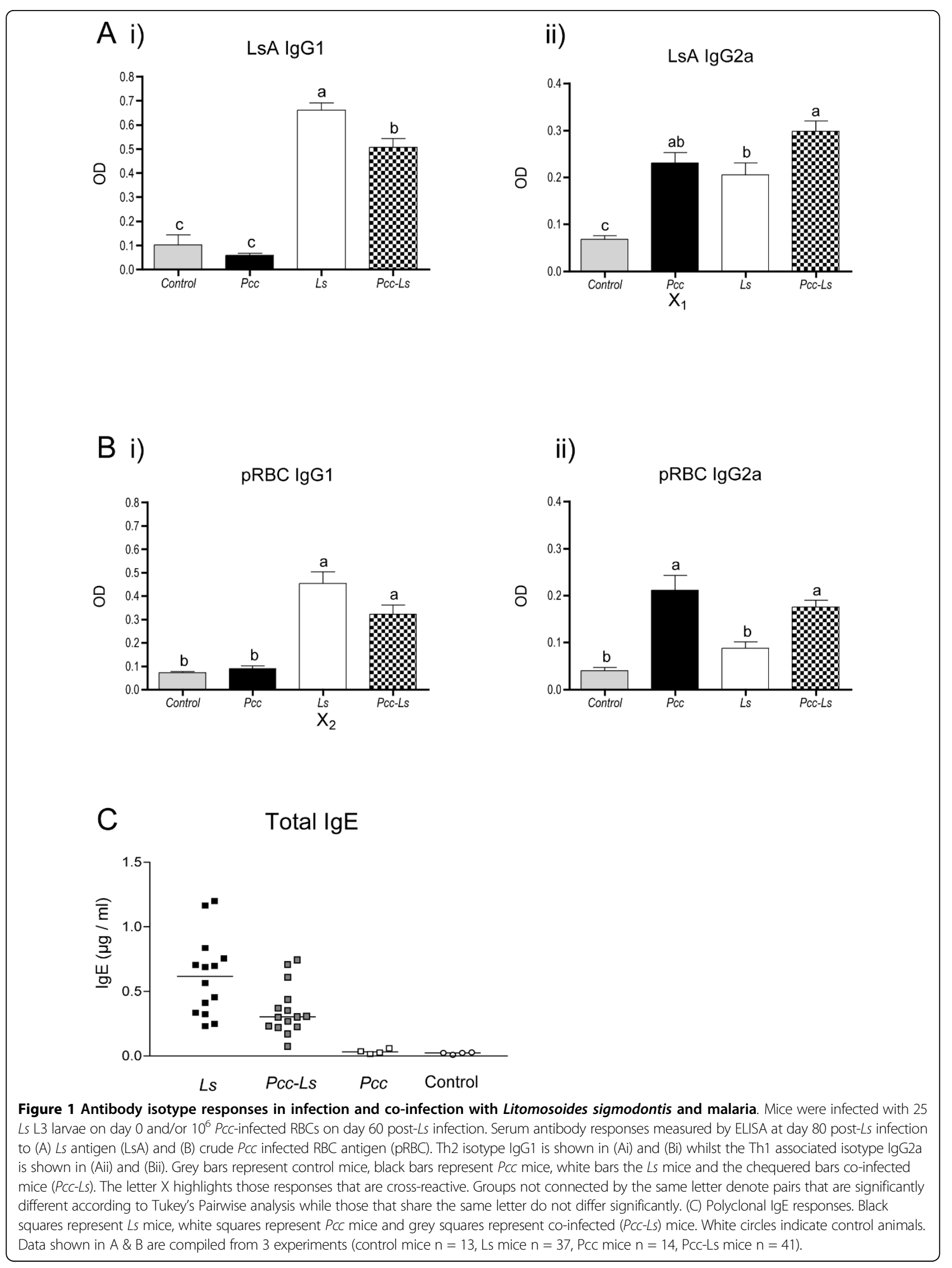


responses. Our observation that there was significant cross-reactivity at the sera dilution tested thus confounded our ability to interpret any changes in immunological bias during Pcc-Ls co-infection.

\section{Cross-reactive antibody responses are also observed during malaria-Nippostrongylus brasiliensis co-infection}

In order to address the utility of antibody isotype responses further, we embarked on co-infection experiments with $P c c$ and the nematode $N b$. Because $P c-N b$ is an acute model, whereby the nematode is cleared by day 7 and the peak of malaria parasitemia is controlled by day 10 , the antibody data could be collected after only 20 days of co-infection, a more practical time frame than the 80 days required for the Pcc-Ls experiments. This also allowed us to address whether our observations of antibody cross-reactivity were a more general feature of Pcc-nematode infection. Given the apparent cross-reactivity observed at a fixed dilution of sera in the Pcc-Ls ELISA we used endpoint titres derived from a serial dilution $(1: 50-1: 819200)$ in the $\mathrm{Pcc}-\mathrm{Nb}$ assays to address whether this readout would overcome crossreactivity problems. To determine if the specificity of the assay could be improved with the use of recombinant antigens we also included the malaria protein, MSP- $1_{19}$ [39] not available to us for the $L s$ studies.

The antibody responses we observed on Day 20 of $\mathrm{Pcc}-\mathrm{Nb}$ co-infection (Fig 2) paralleled those we had seen in the Pcc-Ls experiments at Day 80. For example, as seen in Fig 2Aiii, $N b$ mice made IgG1 biased responses against $\mathrm{NbA}$, and responses in $\mathrm{Pcc}-\mathrm{Nb}$ mice were intermediate between $N b$ and $P c c$ mice. In addition, $P c c$ mice mounted a strong MSP-1 $1_{19}$-specific IgG2a response that was reduced in $\mathrm{Pcc}-\mathrm{Nb}$ mice (Fig 2Bi). As before, levels of polyclonal IgE in $\mathrm{Pcc}-\mathrm{Nb}$ mice were intermediate (data not shown). We again observed cross-reactivity, whereby $\mathrm{Nb}$ mice mounted detectable IgG1 and IgG2a responses to both recombinant and crude malaria antigens (indicated by $\mathrm{X}_{1 \& 2}$ in Fig $2 \mathrm{~A}$ and $\mathrm{X}_{4 \& 5}$ in Fig $2 \mathrm{~B}$, respectively). The magnitude of the $\mathrm{Nb}$ induced IgG2a cross-reactive response is particularly striking with titres against crude and recombinant malaria antigens reaching 2500 and 200 respectively. Similarly, $P c c$ mice mounted responses to $\mathrm{NbA}\left(\mathrm{X}_{3}\right.$ in Fig $2 \mathrm{~A}$ and $\mathrm{X}_{6}$ in Fig $2 \mathrm{~B}$ ). It is important to note that these titres although low are markedly greater than background responses (mean plus 3 standard deviations of serum responses from control mice), which are represented as zero on the y-axis. The immune bias that is apparent in serum antibody isotype responses is fully supported by cytokine responses in the lymph nodes of $\mathrm{Pcc}-\mathrm{Nb}$ infected mice as we have recently described [53]. Of interest, no cross-reactivity was observed at the Tcell level.
Cross-reactive IgG1 responses of malaria-infected mice to $\mathrm{NbA}$ are lost at higher dilutions but lgG2a responses remain

The analysis of both Pcc-Ls and Pcc-Nb co-infection indicates that the issue of cross-reactivity is a factor investigators are likely to routinely encounter. Determining the qualitative and quantitative aspects of the crossreacting antibody responses are not only important for the practical analysis of immune deviation but could be of real biological relevance during co-infection.

As expected, antibody responses were biased, in terms of isotype, by infection status. The bias in isotype due to a particular infection (Th2 associated IgG1 induced during $N b$ infection, for example) was extended to non-specific antigens, as seen in the IgG1 response of $\mathrm{Nb}$ mice to both MSP- $1_{19}$ and pRBC $\left(\mathrm{X}_{1}\right.$ and $\mathrm{X}_{2}$ in Fig $2 \mathrm{Ai}+$ 2Aii). However, $P c c$-specific IgG2a titres in $P c c$ mice were significantly higher than the cross-reactive response induced in $\mathrm{Nb}$ mice (Fig $2 \mathrm{Bi}$ ). Thus, although $\mathrm{Nb}$ mice made cross-reactive IgG2a responses, these were no longer detectable with increasing dilution of sera (Fig 2Bi). In this case capitalising on the differences in strength of antigen-specific and cross-reactive responses clarified interpretation of immune bias in coinfected mice. Similarly, IgG1 responses to NbA were significantly higher in $\mathrm{Nb}$ mice than the cross-reactive response induced by $P c c$ mice (Fig 2Aiii). However, titre of $P c c$-induced cross-reactive IgG2a to NbA did not differ significantly from $\mathrm{Nb}$ mice $\left(\mathrm{X}_{6}\right.$ in Fig 2 Biii).

We can conclude from this analysis that cross-reactive IgG1 responses to $\mathrm{NbA}$ were only detectable at dilutions less than 1:100 and thus higher dilutions may be used to avoid cross-reactivity when assessing antigen-specific antibody isotype profiles for the purpose of interpreting immune bias. However, increasing sera dilution did not always overcome the cross-reactivity observed, as IgG2a responses to $\mathrm{NbA}$ in $P c c$ mice were still observed at $1: 2500$. This cross-reactivity warrants further investigation, as it is likely to be important biologically. Indeed even cross-reactive responses detectable only at high serum concentrations may still have functional relevance in vivo.

\section{Cross-reactivity appears to lie predominantly with carbohydrate epitopes and can be largely eliminated by periodate treatment}

Antibody cross-reactivity in a broad range of systems can be attributed to reactivity with carbohydrate determinants $[54,55]$. Additionally, the IgG3 isotype is often associated with recognition of carbohydrates [56] and we observed cross-reactive IgG3 antibody responses during $\mathrm{Pcc}-\mathrm{Nb}$ co-infection (Fig. 3 ). $\mathrm{Nb}$ mice mounted IgG3 responses to both MSP- $1_{19}$ and pRBC antigens, achieving titres of 200 and 3200 respectively (Fig $3 \mathrm{Ci}$ 

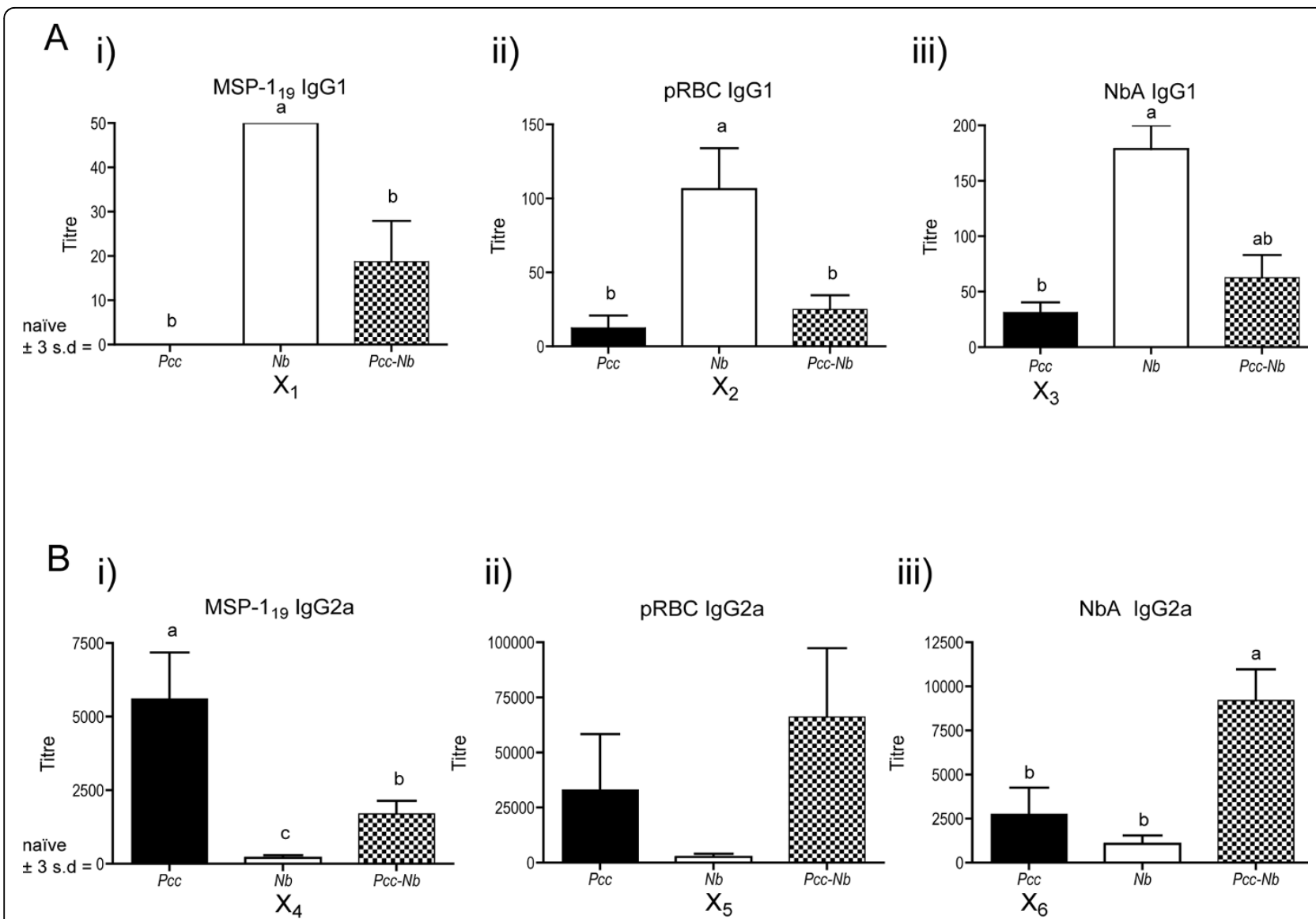

ii)

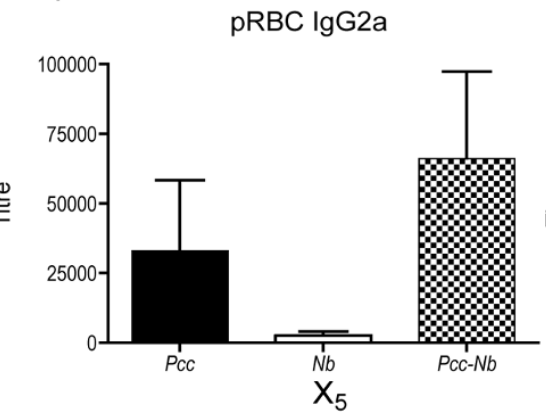

iii)

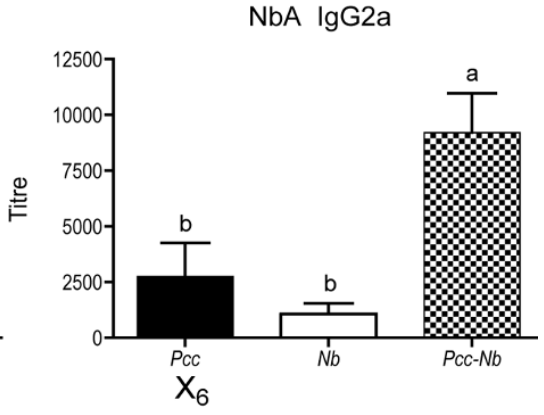

Figure 2 Antibody isotype responses in infection and co-infection with Nippostrongylus brasiliensis and malaria. Mice were infected with 200 Nb L3 larvae and/or $10^{5}$ PCc-infected RBCs on day 0. Serum antibody titres (A) IgG1 (B) IgG2a to recombinant Pcc antigen MSP-1 19 (i), crude $P C c$ antigen ( $P R B C$ ) (ii) and crude Nb antigen (NbA) (iii) were measured at day 20 post-infection for 8 mice per infection group. Black bars represent the PCC mice, white bars the $\mathrm{Nb}$ mice and the chequered bars the co-infected mice (Pcc-Nb). Antibody titres are shown on the $y$-axis and represent the reciprocal of the greatest dilution at which O.D was greater than the mean plus 3 standard deviations of the O.D values observed for control mouse sera at a 1/200 dilution. The letter X highlights those responses that are cross-reactive. Groups not connected by the same letter denote pairs that are significantly different according to Tukey's Pairwise analysis.

and 3Cii). Pcc mice mounted similar cross-reactive IgG3 responses to $\mathrm{NbA}$ (Fig 3Ciii). We thus chose to assess whether cross-reactivity in our $\mathrm{Pcc}-\mathrm{Nb}$ co-infection system could be overcome by periodate treatment of the parasite antigens. Periodate oxidises carbohydrate to aldehydes, thus disrupting carbohydrate epitopes, which allowed us to distinguish if cross-reactive responses target the carbohydrate or protein moiety of an antigen. This could be of particular importance where detection of cross-reactive responses was not overcome by increasing serum dilution. In addition to clarifying the interpretation of shifts in immune bias, determining whether induction of specific isotype responses is driven by protein or carbohydrate recognition has important implications for vaccine design and diagnostic serology.

For the pRBC and MSP-1 19 antigens, periodate treatment did not significantly affect recognition by IgG1 antibodies $(P \geq 0.7)$. Periodate treatment of $\mathrm{NbA}$ however, significantly reduced anti-NbA IgG1 titres across all infection groups (Fig 3Aiii), suggesting common recognition of a carbohydrate moiety. In particular, the cross-reactive recognition of $\mathrm{NbA}$, by IgG1 antibodies from $P c c$ mice, was ablated $\left(\mathrm{X}_{7}\right.$ in Fig 3Aiii).

Treatment of MSP- $1_{19}$ antigen with periodate resulted in a significant increase in IgG2a detected in sera from $\mathrm{Pcc}-\mathrm{Nb}$ mice. Detection of IgG2a in singly-infected mice also followed this trend but was not statistically significant (Fig 3Bi). These results suggest recognition of a protein epitope on the recombinant antigen previously masked by glycosylation. Plasmodium species lack the glycosyltransferases required for any glycosylation other than attachment of GPI anchors [57,58]. However, inappropriate glycosylation of the recombinant protein can occur in the Pichia expression system [57]. The increase in protein-specific responses, following periodate treatment of the recombinant antigen $\left(\mathrm{MSP}-1_{19}\right)$, may thus 


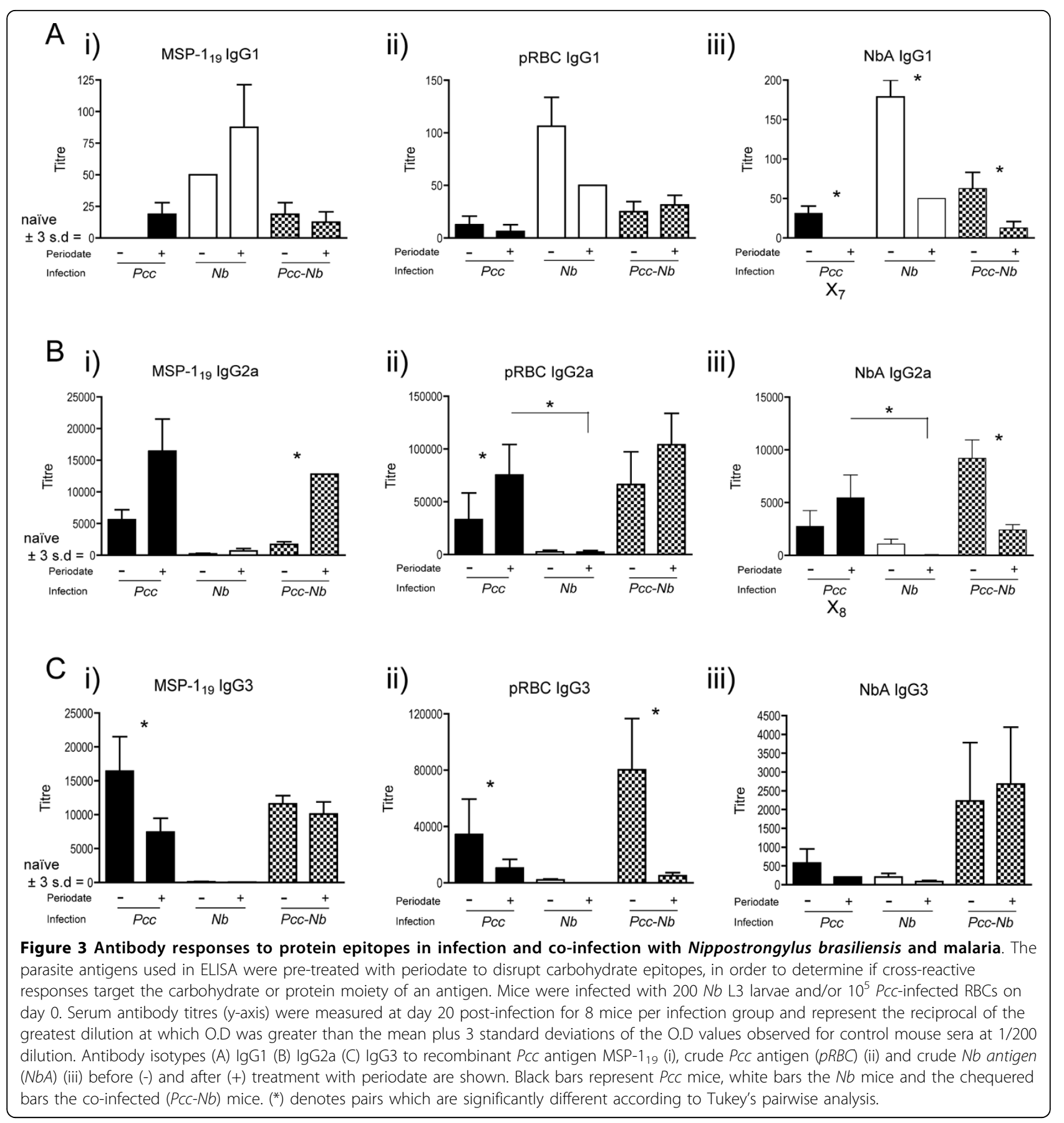

reflect the response to the natural non-glycosylated parasite protein seen during infection. IgG2a recognition of periodate treated $\mathrm{pRBC}$ antigen was enhanced in sera from $P c c$ mice, though not in the $P c c-N b$ or $N b$ mice (Fig 3Bii). This suggests the cross-reactive IgG2a response is not targeting carbohydrates, which could potentially be conserved amongst parasite antigens.

For $\mathrm{NbA}$, it was only after treatment with periodate that differences amongst infection groups become apparent, whereby significantly greater amounts of (cross-reactive) IgG2a antibodies were detected in Pcc mice in comparison to $\mathrm{Nb}$ mice $\left(\mathrm{X}_{8}\right.$ in Fig 3Biii). Thus, the $P c c$-induced cross-reactive IgG2a response to $\mathrm{NbA}$ $\left(\mathrm{X}_{6}\right.$ in Fig 2Biii) that was not lost with serial dilution was also maintained following periodate treatment $\left(\mathrm{X}_{8}\right.$ in Fig 3Biii). In contrast, the $\mathrm{Nb}$-specific IgG2a response appears to target carbohydrate as periodate treatment reduced recognition of $\mathrm{NbA}$ in both $\mathrm{Nb}$ and $\mathrm{Pcc}-\mathrm{Nb}$ 
mice (Fig 3Biii) although only statistically significant in the $\mathrm{Pcc}-\mathrm{Nb}$ mice. This may indicate that atypical Th1type responses to helminth antigens are driven by carbohydrate.

Disruption of carbohydrates via periodate treatment significantly affected the recognition of $P c c$ antigens by IgG3 antibodies. In particular, recognition of periodate treated $\mathrm{pRBC}$ was reduced in serum from all mice that had experienced $P c c$ infection; this was most evident in the $\mathrm{Pcc}-\mathrm{Nb}$ mice (Fig 3Cii). The recognition of periodate treated $\mathrm{MSP}_{-19}$ was also significantly reduced in $P c c$ mice (Fig 3Ci). The more pronounced reduction in IgG3 response to the treated $\mathrm{PRBC}$ antigen may reflect the greater proportion of carbohydrate components in this crude antigen preparation in comparison to the single recombinant protein.

\section{Discussion}

Antibody analysis should be able to provide critical information on changes in cytokine bias due to co-infection. This is particularly important in human studies where serum may be the only reagent available for immunological analysis. Whilst we acknowledge that there is a need to confirm the relationship between splenic or serum cytokines and antibody responses in coinfection if this strategy is to be used in human studies, our focus is on the interpretation of antigen-specific Th1/Th2 bias based on antibody isotype, which was complicated by cross-reactivity in the two co-infection models studied here. It is worth noting that cross-reactive responses were observed regardless of whether recombinant or crude antigens were used. We primarily address technical strategies that will enable us, and others, to draw conclusions regarding the influence of a co-infecting parasite on immune bias using serum antibodies. However, the functional implications of crossreactive responses are also discussed.

Murine models that aim to dissect the real effect of a co-infecting parasite on immune bias must use large numbers of animals to detect significant differences in antigen-specific responses between single and dual infection. Thus for antibody analysis of the large sample size (see legend Fig 1 for details) in our Pcc-Ls study of co-infection we chose a fixed serum concentration, previously determined to fall within the linear range of the dilution curve. Although this saved time and reagents, in retrospect, it provided insufficient information for our purposes: it did not allow us to distinguish the relative strengths of cross-reactive versus antigen-specific responses.

When antibody titres were calculated in the $\mathrm{Pcc}-\mathrm{Nb}$ study, we were able to determine whether apparent alterations in antibody isotype profile on co-infection were due to actual changes in parasite-specific responses or reflected a cross-reactive response. For example, determining that cross-reactive IgG2a antibody titres in $\mathrm{Nb}$ mice $\left(\mathrm{X}_{4}\right.$ in Fig $\left.2 \mathrm{Bi}\right)$ were significantly lower than the antigen-specific response of $P c c$ mice meant that cross-reactivity was unlikely to influence the titre observed in $\mathrm{Pcc}-\mathrm{Nb}$ mice. This allowed us to conclude that the reduction in Th1 type antibody in $\mathrm{Pcc}-\mathrm{Nb}$ mice was probably due to suppression of $P c c$-specific Th1 responses by nematode infection. Further to this, had we not calculated titre and relied on optical density data derived from a single dilution of sera we may not have observed the difference between $P c c$ and $P c c-N b$ mice and thus incorrectly concluded that there was no effect of co-infection on Th1 responses. Similarly, analysis of antibody titre enabled us to detect the reduction in antiNbA IgG1 antibody in $\mathrm{Pcc}-\mathrm{Nb}$ mice (Fig 2Aiii), which suggests a $P c c$-mediated bias toward a Th1 cell response. In other cases, cross-reactivity was observed even at high dilutions with $P c c$ mice achieving IgG2a titres equivalent to or greater than $\mathrm{Nb}$ mice $\left(\mathrm{X}_{6}\right.$ in Fig 2Biii). In this case, calculation of titre did not help to unravel potential cytokine influences and the enhanced IgG2a response in co-infected mice may be due to increased Th1 cytokines during co-infection and/or the presence of cross-reactive antibody (Fig 2Biii).

Nematode surface antigens and the excretory/secretory products from these parasites are heavily glycosylated [59]. Similarly, Plasmodium species express glycoconjugates on their surface and have abundant glycophosphatidylinositol anchors [60]. In other co-infection systems cross-reactive epitopes have been shown to derive from carbohydrate structures [61]. The sensitivity of the carbohydrate component of an antigen to periodate treatment [59] has been beneficial in interpreting our results. In particular, treatment of $P c c$ antigens demonstrated that cross-reactive nematode-induced IgG3 responses were largely attributed to the carbohydrate component. Interestingly, periodate treatment also reduced apparent cross-reactivity by exposure of protein epitopes, previously masked by carbohydrate, which enhanced the detection of antibodies from mice that had been exposed to the antigen during infection (e.g., anti-pRBC in Fig 3Bii). This allowed us to conclude that levels of anti-pRBC IgG2a antibody in $\mathrm{Pcc}-\mathrm{Nb}$ mice are solely induced by the $P c c$ parasite. Further to this, detection of cross-reactive protein-specific antibodies enabled responses, previously indistinguishable in magnitude between singly-infected groups, to be differentiated. For example, periodate treatment of $\mathrm{NbA}$ enhanced detection of Pcc induced cross-reactive IgG2a antibodies $\left(\mathrm{X}_{8}\right.$ in Fig 3Biii) whilst the antigen-specific response of $\mathrm{Nb}$ mice was ablated. This indicates that the level of $\mathrm{Nb}$ specific IgG2a observed in $\mathrm{Pcc}-\mathrm{Nb}$ mice is due to $\mathrm{Pcc}$ driving a cross-reactive IgG2a Th1 type response. 
We have demonstrated that the use of serial dilutions and periodate treatment of the parasite antigens can help overcome cross-reactivity for the purposes of analysing and interpreting Th1/Th2 cell immune bias. However, some 'true' cross-reactivity remained (i.e. Pccinduced IgG2a responses to NbA (Fig 2Biii/Fig 3Biii)), and the induction of these antibodies has important implications with regard to biological function. For example the immune responses to nematode infection are typically characterised by a Th2 type (IgG1) response, as we observed for $\mathrm{Nb}$-induced responses to the nematode antigen (NbA). The propensity for Pcc mice to induce atypical IgG2a antibody isotypes to nematode antigen is likely due to the malaria parasite promoting Th1 cytokines in the environment where the antibody response is established [45]. The biological consequences of the Pcc driven IgG2a response to the nematode antigen and the less pronounced IgG1 response of $\mathrm{Nb}$ mice to $\mathrm{Pcc}$ antigens remain to be investigated. In Trichuris muris infection, manipulation of the immune environment to a Th1 type setting, characterised by elevated IgG2a and IFN $\gamma$, was shown to enhance chronicity of this intestinal helminth [62]. Pccinduced IgG2a to nematode antigens may thus have real consequences in terms of disease outcome. Effects of nematode co-infection on the malaria parasite are also evident; $\mathrm{Pcc}-\mathrm{Nb}$ mice have reduced levels of malaria parasitemia in comparison to Pcc mice [53] and it is interesting to consider the possibility that cross-reactive IgG2a antibodies induced by the nematode infection may act in concert with the antigen-specific response to control malaria parasites. The potential for cross-reactive responses to have a functional role during infection raises the intriguing possibility that their production is a deliberate strategy of the host to combat diverse parasites [63]. To fully understand the relative contribution of cross-reactive antibodies in parasite control would require passive antibody transfer experiments.

Although schistosome parasites are phylogenetically distinct from nematodes, helminth co-infection studies that investigate Schistosoma mansoni provide evidence that cross-reactivity is relevant in other co-infection systems and can have a strong impact on disease severity. Naus et al [43] report the induction of crossreactive IgG3 antibodies that recognise both Plasmodium falciparum and S. mansoni antigens. Pierrot et al extended this study, identifying the $S$. mansoni antigen (SmLRR) that is recognised by both malaria and $S$. mansoni singly-infected hosts. Interestingly, as we observed in our $\mathrm{Pcc}-\mathrm{Nb}$ model of co-infection, the two infections induce different antibody isotypes to antigen: cross-reactive malaria driven IgG3 and helminth driven IgG4 [45]. In areas co-endemic for these two parasites, exposure to malaria and subsequent induction of the cross-reactive IgG3 response seems to increase the risk of developing hepatosplenomegaly in schistosome infected individuals [44].

\section{Conclusions}

In summary, our data illustrate that whilst cross-reactivity may confound observations of interest, it can largely be overcome by a combination of increasing sera dilution and pre-treatment of antigens with periodate. Adopting such strategies will enable antibody isotypes to be used as an indicator of cytokine bias and clarify interpretation of when Th1-Th2 cell shifts have occurred as a result of co-infection. Arising from this analysis is the opportunity to dissect antigen-specific from cross-reactive responses and thus obtain information pertaining to the relative strength of these responses and recognition of carbohydrate versus protein epitopes. This will provide the foundation on which to base more detailed characterisation of the antibody responses during co-infection in order to investigate their functionality.

\section{Abbreviations}

Ls: (Litomosoides sigmodontis); Nb: (Nippostrongylus brasiliensis); PcC: (Plasmodium chabaudi chabaudi); LSA: (Litomosoides sigmodontis crude antigen); NbA: (Nippostrongylus brasiliensis crude antigen); pRBC: (PCC parasitized red blood cell crude antigen); MSP-1 19: (Merozoite Surface Protein $\left.-1{ }_{19}\right) ;$ RBC: (Red Blood Cell); Th: (T helper); pi: (post-infection).

\section{Acknowledgements}

This work was supported by the MRC-UK, the BBSRC (grant BB/C508734/1 to JEA and ALG, and fellowship BB/D01977X/1 to ALG) and the European Commission (grant ICA4-CT1999-10002).

We thank A. McDonald and D. Cavanagh for their helpful comments and R. Maizels and $\mathrm{Y}$. Harcus for providing us with $\mathrm{Nb}$ infective larvae. In addition, we thank the animal house staff for husbandry.

\section{Author details}

'Institutes of Evolution, Immunology and Infection Research, School of Biological Sciences, King's Buildings, University of Edinburgh, West Mains Road, Edinburgh, EH9 3JT, UK. ${ }^{2}$ Current address: School of Biological Sciences, The University of Reading, Reading, Berks RG6 6UB, UK. ${ }^{3}$ Division of Parasitology, National Institute for Medical Research, The Ridgeway Mill Hill, NW7 1AA, UK. ${ }^{4}$ Department of Ecology and Evolutionary Biology, Princeton University, Princeton, NJ 08544, USA.

\section{Authors' contributions}

KFC participated in the design of the study, conducted the PCC-Nb experiments and immunoassays, performed the statistical analysis and helped to draft the manuscript. TL conducted the Pcc-Ls experiments and immunoassays. JL provided recombinant MSP- $1_{19}$. ALG conceived of the study and participated in its design, was involved in all co-infection experiments and helped to draft the manuscript. JEA also conceived of the study, participated in its design and helped to draft the manuscript. All authors read and approved the manuscript.

Received: 16 September 2009

Accepted: 17 February 2010 Published: 17 February 2010

\section{References}

1. Hartgers FC, Obeng BB, Kruize YC, Dijkhuis A, McCall M, Sauerwein RW, Luty AJ, Boakye DA, Yazdanbakhsh M: Responses to malarial antigens are altered in helminth-infected children. J Infect Dis 2009, 199:1528-35. 
2. Yatich NJ, Yi J, Agbenyega T, Turpin A, Rayner JC, Stiles JK, Ellis WO, Funkhouser E, Ehiri JE, Williams JH, Jolly PE: Malaria and intestinal helminth co-infection among pregnant women in Ghana: prevalence and risk factors. Am J Trop Med Hyg 2009, 80:896-901.

3. NJ Faye B, Tine RC, Lô AC, Gaye O: [Interaction between malaria and intestinal helminthiasis in Senegal: influence of the carriage of intestinal parasites on the intensity of the malaria infection]. Bulletin de la Societe pathologie exotique 2008, 101:391-394.

4. Mwangi TW, Bethony JM, Brooker S: Malaria and helminth interactions in humans: an epidemiological viewpoint. Ann Trop Med Parasitol 2006, 100:551-70.

5. Piessens WF, Hoffman SL, Ratiwayanto S, Piessens PW, Partono F, Kurniawan L, Marwoto HA: Opposing effects of filariasis and chronic malaria on immunoregulatory T lymphocytes. Diagn Immunol 1983, 1:257-60.

6. Guderian RH, Anselmi M, Beck BJ, Mackenzie CD, Williams JF, Proano JR, Cooper PJ: The effect of antimalarial chloroquine therapy and prophylaxis on concurrent infection with Onchocerca volvulus in Ecuador. Trans R Soc Trop Med Hyg 1991, 85:634-8.

7. Ghosh SK, Yadav RS: Naturally acquired concomitant infections of bancroftian filariasis and human plasmodia in Orissa. Indian J Malariol 1995, 32:32-6.

8. Ravindran B, Sahoo PK, Dash AP: Lymphatic filariasis and malaria: concomitant parasitism in Orissa, India. Trans R Soc Trop Med Hyg 1998, 92:21-3

9. Chadee DD, Rawlins SC, Tiwari TS: Short communication: concomitant malaria and filariasis infections in Georgetown, Guyana. Trop Med Int Health 2003, 8:140-3.

10. Nacher $M$, Singhasivanon $P$, Yimsamran $S$, Manibunyong $W$ Thanyavanich N, Wuthisen R, Looareesuwan S: Intestinal helminth infections are associated with increased incidence of Plasmodium falciparum malaria in Thailand. J Parasitol 2002, 88:55-8.

11. Booth M, Vennervald BJ, Kenty L, Butterworth AE, Kariuki HC, Kadzo H, Ireri E, Amaganga C, Kimani G, Mwatha JK, Otedo A, Ouma JH, Muchiri E, Dunne DW: Micro-geographical variation in exposure to Schistosoma mansoni and malaria, and exacerbation of splenomegaly in Kenyan school-aged children. BMC Infect Dis 2004, 4:13.

12. Le Hesran JY, Akiana J, Ndiaye el HM, Dia M, Senghor P, Konate L: Severe malaria attack is associated with high prevalence of Ascaris lumbricoides infection among children in rural Senegal. Trans $R$ Soc Trop Med Hyg 2004, 98:397-9.

13. Lyke KE, Dicko A, Dabo A, Sangare L, Kone A, Coulibaly D, Guindo A, Traore K, Daou M, Diarra I, Sztein MB, Plowe CV, Doumbo OK: Association of Schistosoma haematobium infection with protection against acute Plasmodium falciparum malaria in Malian children. Am J Trop Med Hyg 2005, 73:1124-30.

14. Sokhna C, Le Hesran JY, Mbaye PA, Akiana J, Camara P, Diop M, Ly A, Druilhe $P$ : Increase of malaria attacks among children presenting concomitant infection by Schistosoma mansoni in Senegal. Malar J 2004, $3: 43$.

15. Spiegel A, Tall A, Raphenon G, Trape JF, Druilhe P: Increased frequency of malaria attacks in subjects co-infected by intestinal worms and Plasmodium falciparum malaria. Trans R Soc Trop Med Hyg 2003, 97:198-9.

16. Hotez PJ, Molyneux DH, Fenwick A, Ottesen E, Ehrlich Sachs S, Sachs JD: Incorporating a rapid-impact package for neglected tropical diseases with programs for HIV/AIDS, tuberculosis, and malaria. PLoS Med 2006, 3: e102.

17. Helmby H, Kullberg M, Troye-Blomberg M: Altered immune responses in mice with concomitant Schistosoma mansoni and Plasmodium chabaudi infections. Infect Immun 1998, 66:5167-74.

18. Su Z, Segura M, Morgan K, Loredo-Osti JC, Stevenson MM: Impairment of protective immunity to blood-stage malaria by concurrent nematode infection. Infect Immun 2005, 73:3531-9.

19. De Souza JB, Williamson $\mathrm{KH}$, Otani $\mathrm{T}$, Playfair $\mathrm{JH}$ : Early gamma interferon responses in lethal and nonlethal murine blood-stage malaria. Infect Immun 1997, 65:1593-8.

20. Yoshida A, Maruyama H, Kumagai T, Amano T, Kobayashi F, Zhang M, Himeno K, Ohta N: Schistosoma mansoni infection cancels the susceptibility to Plasmodium chabaudi through induction of type 1 immune responses in A/J mice. Int Immunol 2000, 12:1117-25.
21. Graham AL, Lamb TJ, Read AF, Allen JE: Malaria-filaria coinfection in mice makes malarial disease more severe unless filarial infection achieves patency. J Infect Dis 2005, 191:410-21.

22. Ahvazi BC, Jacobs $P$, Stevenson MM: Role of macrophage-derived nitric oxide in suppression of lymphocyte proliferation during blood-stage malaria. J Leukoc Biol 1995, 58:23-31.

23. Collins JT, Dunnick WA: Germline transcripts of the murine immunoglobulin gamma 2a gene: structure and induction by IFNgamma. Int Immunol 1993, 5:885-91.

24. Paul WE, Brown M, Hornbeck P, Mizuguchi J, Ohara J, Rabin E, Snapper C, Tsang W: Regulation of B-lymphocyte activation, proliferation, and differentiation. Ann N Y Acad Sci 1987, 505:82-9.

25. Else KJ, Finkelman FD: Intestinal nematode parasites, cytokines and effector mechanisms. Int J Parasitol 1998, 28:1145-58.

26. Purkerson JM, Isakson PC: Interleukin 5 (IL-5) provides a signal that is required in addition to IL-4 for isotype switching to immunoglobulin (Ig) G1 and lgE. J Exp Med 1992, 175:973-82.

27. Li BW, Rush A, Zhang SR, Curtis KC, Weil GJ: Antibody responses to Brugia malayi antigens induced by DNA vaccination. Filaria J 2004, 3:1.

28. Arnold H, Bumann D, Felies M, Gewecke B, Sorensen M, Gessner JE, Freihorst J, von Specht BU, Baumann U: Enhanced immunogenicity in the murine airway mucosa with an attenuated Salmonella live vaccine expressing OprF-Oprl from Pseudomonas aeruginosa. Infect Immun 2004, 72:6546-53.

29. Taylor JM, Ziman ME, Fong J, Solnick JV, Vajdy M: Possible Correlates of Long-Term Protection against Helicobacter pylori following Systemic or Combinations of Mucosal and Systemic Immunizations. Infect Immun 2007, 75:3462-9.

30. Da'Dara AA, Skelly PJ, Walker CM, Harn DA: A DNA-prime/protein-boost vaccination regimen enhances $T h 2$ immune responses but not protection following Schistosoma mansoni infection. Parasite Immunol 2003, 25:429-37.

31. von der Weid T, Honarvar N, Langhorne J: Gene-targeted mice lacking B cells are unable to eliminate a blood stage malaria infection. $J$ Immunol 1996, 156:2510-6.

32. Cavinato RA, Bastos KR, Sardinha LR, Elias RM, Alvarez JM, d'Imperio Lima MR: Susceptibility of the different developmental stages of the asexual (schizogonic) erythrocyte cycle of Plasmodium chabaudi chabaudi to hyperimmune serum, immunoglobulin (lg)G1, IgG2a and $F$ (ab')2 fragments. Parasite Immunol 2001, 23:587-97.

33. Mota MM, Brown KN, Holder AA, Jarra W: Acute Plasmodium chabaudi chabaudi malaria infection induces antibodies which bind to the surfaces of parasitized erythrocytes and promote their phagocytosis by macrophages in vitro. Infect Immun 1998, 66:4080-6.

34. Roussilhon C, Oeuvray C, Muller-Graf C, Tall A, Rogier C, Trape JF, Theisen M, Balde A, Perignon JL, Druilhe P: Long-term clinical protection from falciparum malaria is strongly associated with $\lg \mathrm{G} 3$ antibodies to merozoite surface protein 3. PLoS Med 2007, 4:e320.

35. Su Z, Segura M, Stevenson MM: Reduced Protective Efficacy of a BloodStage Malaria Vaccine by Concurrent Nematode Infection. Infection and Immunity 2006, 74:2138-2144.

36. Beale GH, Carter R, Walliker D: Genetics. Rodent Malaria London, Academic PressKillick-Kendrick R, Peters W 1978, 213-245.

37. Diagne M, Petit G, Liot P, Cabaret J, Bain O: The filaria Litomosoides galizai in mites; microfilarial distribution in the host and regulation of the transmission. Ann Parasitol Hum Comp 1990, 65:193-9.

38. Lawrence RA, Gray CA, Osborne J, Maizels RM: Nippostrongylus brasiliensis: cytokine responses and nematode expulsion in normal and IL-4-deficient mice. Exp Parasitol 1996, 84:65-73.

39. Hensmann M, Li C, Moss C, Lindo V, Greer F, Watts C, Ogun SA, Holder AA, Langhorne J: Disulfide bonds in merozoite surface protein 1 of the malaria parasite impede efficient antigen processing and affect the in vivo antibody response. Eur J Immunol 2004, 34:639-48.

40. Grafen A, Hails R: Modern Statistics for the Life Sciences. Oxford University Press 2007.

41. Tetsutani K, Ishiwata K, Ishida H, Tu L, Torii M, Hamano S, Himeno K, Hisaeda $\mathrm{H}$ : Concurrent infection with Heligmosomoides polygyrus suppresses anti-Plasmodium yoelii protection partially by induction of CD4(+)CD25(+)Foxp3(+) Treg in mice. Eur J Immunol 2009, 39(10):2822-30.

42. Miller CM, Smith NC, Ikin RJ, Boulter NR, Dalton JP, Donnelly S: Immunological interactions between 2 common pathogens, Th1- 
inducing protozoan Toxoplasma gondii and the Th2-inducing helminth Fasciola hepatica. PLoS One 2009, 4:e5692.

43. Naus CW, Jones FM, Satti MZ, Joseph S, Riley EM, Kimani G, Mwatha JK, Kariuki $\mathrm{CH}$, Ouma JH, Kabatereine NB, Vennervald BJ, Dunne DW: Serological responses among individuals in areas where both schistosomiasis and malaria are endemic: cross-reactivity between Schistosoma mansoni and Plasmodium falciparum. J Infect Dis 2003, 187:1272-82.

44. Mwatha JK, Jones FM, Mohamed G, Naus CW, Riley EM, Butterworth AE, Kimani G, Kariuki CH, Ouma JH, Koech D, Dunne DW: Associations between anti-Schistosoma mansoni and anti-Plasmodium falciparum antibody responses and hepatosplenomegaly, in Kenyan schoolchildren. $J$ Infect Dis 2003, 187:1337-41.

45. Pierrot C, Wilson S, Lallet H, Lafitte S, Jones FM, Daher W, Capron M, Dunne DW, Khalife J: Identification of a novel antigen of Schistosoma mansoni shared with Plasmodium falciparum and evaluation of different cross-reactive antibody subclasses induced by human schistosomiasis and malaria. Infect Immun 2006, 74:3347-54.

46. Remoue F, Diallo TO, Angeli V, Herve M, de Clercq D, Schacht AM, Charrier N, Capron M, Vercruysse J, Ly A, Capron A, Riveau G: Malaria coinfection in children influences antibody response to schistosome antigens and inflammatory markers associated with morbidity. Trans $R$ Soc Trop Med Hyg 2003, 97:361-4.

47. Mutapi F, Ndhlovu PD, Hagan P, Woolhouse ME: Anti-schistosome antibody responses in children coinfected with malaria. Parasite Immunol 2000, 22:207-9.

48. Rodriguez M, Terrazas LI, Marquez R, Bojalil R: Susceptibility to Trypanosoma cruzi is modified by a previous non-related infection. Parasite Immunol 1999, 21:177-85.

49. Marechal P, Le Goff L, Hoffman W, Rapp J, Oswald IP, Ombrouck C, Taylor DW, Bain O, Petit G: Immune response to the filaria Litomosoides sigmodontis in susceptible and resistant mice. Parasite Immunol 1997, 19:273-9.

50. Le Goff L, Martin C, Oswald IP, Vuong PN, Petit G, Ungeheuer MN, Bain O: Parasitology and immunology of mice vaccinated with irradiated Litomosoides sigmodontis larvae. Parasitology 2000, 120(Pt 3):271-80.

51. Lawrence RA, Allen JE, Osborne J, Maizels RM: Adult and microfilarial stages of the filarial parasite Brugia malayi stimulate contrasting cytokine and Ig isotype responses in BALB/c mice. J Immunol 1994, 153:1216-24.

52. Su Z, Stevenson MM: IL-12 is required for antibody-mediated protective immunity against blood-stage Plasmodium chabaudi AS malaria infection in mice. J Immunol 2002, 168:1348-55.

53. Hoeve MA, Mylonas KJ, Fairlie-Clarke KJ, Mahajan SM, Allen JE, Graham AL: Plasmodium chabaudi limits early Nippostrongylus brasiliensis-induced pulmonary immune activation and Th2 polarization in co-infected mice. BMC Immunol 2009, 10:60

54. Paschinger K, Fabini G, Schuster D, Rendic D, Wilson IB: Definition of immunogenic carbohydrate epitopes. Acta Biochim Pol 2005, 52:629-32.

55. Xu BX, Powell MR: Carbohydrate epitopes are responsible for antibody cross-reactivity in Trypanosoma cruzi-infected mice. J Parasitol 1991, 77:808-10.

56. Snapper CM, Mclntyre TM, Mandler R, Pecanha LM, Finkelman FD, Lees A, Mond JJ: Induction of IgG3 secretion by interferon gamma: a model for $\mathrm{T}$ cell-independent class switching in response to $\mathrm{T}$ cell-independent type 2 antigens. J Exp Med 1992, 175:1367-71.

57. von Itzstein M, Plebanski M, Cooke BM, Coppel RL: Hot, sweet and sticky: the glycobiology of Plasmodium falciparum. Trends Parasitol 2008, 24:210-8.

58. Mendonca-Previato L, Todeschini AR, Heise N, Previato JO: Protozoan parasite-specific carbohydrate structures. Curr Opin Struct Biol 2005, 15:499-505.

59. Dell A, Haslam SM, Morris HR, Khoo KH: Immunogenic glycoconjugates implicated in parasitic nematode diseases. Biochim Biophys Acta 1999, 1455:353-62.

60. McConville MJ, Ferguson MA: The structure, biosynthesis and function of glycosylated phosphatidylinositols in the parasitic protozoa and higher eukaryotes. Biochem J 1993, 294(Pt 2):305-24.

61. van Remoortere A, Bank CM, Nyame AK, Cummings RD, Deelder AM, van Die I: Schistosoma mansoni-infected mice produce antibodies that crossreact with plant, insect, and mammalian glycoproteins and recognize the truncated biantennaryN-glycan Man3GIcNAc2-R. Glycobiology 2003, 13:217-25.

62. Else KJ, Finkelman FD, Maliszewski CR, Grencis RK: Cytokine-mediated regulation of chronic intestinal helminth infection. J Exp Med 1994, 179:347-51.

63. Fairlie-Clarke K, Shuker DM, Graham AL: Why do adaptive immune responses cross-react?. Evolutionary Applications 2009, 2(1):122-131.

doi:10.1186/1471-2172-11-6

Cite this article as: Fairlie-Clarke et al:: Antibody isotype analysis of malaria-nematode co-infection: problems and solutions associated with cross-reactivity. BMC Immunology 2010 11:6.

\section{Submit your next manuscript to BioMed Central and take full advantage of:}

- Convenient online submission

- Thorough peer review

- No space constraints or color figure charges

- Immediate publication on acceptance

- Inclusion in PubMed, CAS, Scopus and Google Scholar

- Research which is freely available for redistribution

Submit your manuscript at www.biomedcentral.com/submit
C Biomed Central 